\title{
Reconsideration of Anopheles rivulorum as a vector of Plasmodium falciparum in Western Kenya: some evidence from biting time, blood preference, sporozoite positive rate, and pyrethroid resistance
}

Hitoshi Kawada ${ }^{1 *}$, Gabriel O Dida ${ }^{2,3}$, George Sonye ${ }^{3}$, Sammy M Njenga ${ }^{4}$, Charles Mwandawiro ${ }^{5}$ and Noboru Minakawa ${ }^{1,6}$

\begin{abstract}
Background: Anopheles gambiae, An. arabiensis, and An. funestus are widespread malaria vectors in Africa. Anopheles rivulorum is the next most widespread species in the An. funestus group. The role of An. rivulorum as a malaria vector has not been fully studied, although it has been found to be a minor or opportunistic transmitter of Plasmodium falciparum.

Methods: Mosquitoes were collected indoors over a 12-hour period using a light source attached to a rotating bottle collector in order to determine peak activity times and to provide DNA for meal source identification. Gravid female mosquitoes were collected indoors via an aspirator to generate F1 progeny for testing insecticidal susceptibility. Blood meal sources were identified using a multiplexed PCR assay for human and bovine cytochrome-B, and by matching sequences generated with primers targeting vertebrate and mammalian cytochrome-B segments to the Genbank database.

Results: Anopheles rivulorum fed on human blood in the early evening between 18:00 and 20:00, when insecticide-treated bed nets are not in use, and the presence of Plasmodium falciparum sporozoites in $0.70 \%$ of the An. rivulorum individuals tested was demonstrated. Susceptibility to permethrin, deltamethrin, and DDT is higher in An. rivulorum (84.8\%, 91.4\%, and 100\%, respectively) than in An. funestus s.s. (36.8\%, 36.4\%, and 70\%, respectively), whereas mortality rates for propoxur and fenitrothion were 100\% for both species. Resistance to pyrethroids was very high in An. funestus s.s. and the potential of the development of high resistance was suspected in $A n$. rivulorum.
\end{abstract}

Conclusion: Given the tendency for An. rivulorum to be active early in the evening, the presence of $P$. falciparum in the species, and the potential for the development of pyrethroid resistance, we strongly advocate reconsideration of the latent ability of this species as an epidemiologically important malaria vector.

Keywords: Permethrin, Deltamethrin, Resistance, Anopheles rivulorum, Anopheles funestus, Plasmodium falciparum, Kenya

\footnotetext{
* Correspondence: vergiss@nagasaki-u.ac.jp

'Department of Vector Ecology \& Environment, Institute of Tropical

Medicine, Nagasaki University, Nagasaki, Japan

Full list of author information is available at the end of the article
} 


\section{Background}

Anopheles gambiae Giles, An. arabiensis Patton, and An. funestus Giles are widespread malaria vectors in Africa. Both An. gambiae s.s. and An. funestus s.s. are highly anthropophilic [1,2], while An. arabiensis prefers to feed on humans but will feed on other hosts as well [3]. A fourth species, An. rivulorum Leeson, is the next most widespread species in the An. funestus group [4]. The role of $A n$. rivulorum as a malaria vector has not been fully studied [5-10]. Previous studies have demonstrated that An. rivulorum has the potential to replace other major malarial vectors such as An. funestus s.s. after spraying of indoor insecticides eliminates the more abundant species [11].

The use of insecticide-treated bed nets (ITNs) is a simple and inexpensive self-protection measure against malaria, which has been shown to reduce the morbidity of children ( $<5$ years old) by $50 \%$ and global child mortality by $20 \%-30 \%[12,13]$. The dramatic reduction in malaria transmission in Kenya [13] may be due to fewer opportunities for the major anthropophilic and endophagous vectors to feed successfully on humans. However, the increase in the use of ITNs in Kenya has led to an increase in insecticide resistance [14-16] and in the replacement of vector species [17].

This study reports the vectorial and behavioral characteristics and the insecticide susceptibility of An. rivulorum in western Kenya, and strongly recommends a reevaluation of this species as a minor vector of $P$. falciparum. A large portion of the paper reports on insecticide susceptibility as well.

\section{Methods}

\section{Study area}

The Gembe East area in the Mbita District of Nyanza Province in western Kenya was used as the study area. The area is drier in the eastern part of the district, and becomes progressively wetter towards the higher altitudes in the western parts of Gwassi Hills and Mfangano Island. In the highlands, the rainfall ranges between $800-1900 \mathrm{~mm}$ per annum, while the lowlands receive slightly less at $800-1200 \mathrm{~mm}$ each year. The rainfall pattern in the area is bimodal, with the long rainy season occurring from March through May, and the short rainy season occurring in November and December. Malaria infection rates rise steadily between September and February and peak briefly in June, following the long rains [18]. The Mbita and Suba districts are 2 focal points identified as high vector transmission areas in Kenya, and more than $50 \%$ of the population is exposed to malaria at a rate of $\geq 40 \%$ $P f \mathrm{PR}_{2-10}$ ( $P f$ parasite rate corrected to a standard agerange of 2 to less than 10 years old) [19]. Efforts have recently been renewed in this area to increase the use of effective preventative measures such as ITNs and combined vector control approaches. The Akado Medical Centre Project Mosquito Net, the Power of Love Foundation in partnership with World Swim Against Malaria, and the Ministry of Health distributed 6000 ITNs to children under 5 years of age and to pregnant women in the Gembe area. This increased the ITN coverage rate by at least $35 \%$, from $17 \%$ to $52 \%$.

\section{Adult mosquito collection and rearing of $\mathrm{F} 1$ progenies}

Indoor adult collections took place in Nyandago, Nyaroya, Akuot, Alala, Alero, Kirindo, Ngou, and Uwi village in the Gembe East area on the shores of Lake Victoria. The house residents were informed about the study and their written consent was obtained before mosquito collection. Collections were performed during February 5-11, 2010; April 19-June 10, 2010; September 13-October 28, 2010; and January 27-February 4, 2012. Collections were done with a battery-powered aspirator (C-cell Aspirator, BioQuip Products, Rancho Dominguez, CA, USA) between 07:00-09:00 by 3 persons. After collection, gravid females were individually confined into a 20 $\mathrm{ml}$ glass vial containing $2 \mathrm{ml}$ of water. A strip of filter paper (ca $3 \times 4 \mathrm{~cm}$ ) was placed inside each vial to collect eggs. Hatched larvae were reared with dechlorinated tap water until adult emergence. Larvae were fed a mixture of powdered animal food (CE-2; Clea Inc., Tokyo, Japan.) and dried yeast (Ebios ${ }^{\circledR}$; Mitsubishi Tanabe Pharma, Tokyo, Japan). Grass leaves were added to rearing water containing An. funestus s.s. and An. rivulorum larvae to provide a resting place. The containers were exposed to sunlight to facilitate phytoplankton growth as a larval food resource [20]. Unfed F1 female adults were used for insecticide susceptibility tests.

\section{Adult mosquito collection by miniature light traps equipped with collection bottle rotators}

Indoor mosquito trapping was done with 6 sets of the Center for Disease Control (CDC) miniature light trap (Model 512) equipped with a collection bottle rotator (Model 1512) (John W. Hock Co., Gainesville, FL, USA) in 3 houses in Nyaroya village and 4 houses in Nyandago village from September 16-October 5, 2010 and July 11-18, 2012. The house residents were informed about the study and their written consent was obtained before mosquito collection. The collection bottle rotator, which has 8 separate plastic collection bottles, was programmed to collect active mosquitoes at 2-hour intervals between 16:00-08:00. The traps were placed in the corner of the living room as far apart from the places where people sleep as possible. Female mosquitoes were identified and classified as unfed, blood-fed, and gravid. The abdominal contents of 
fed females were used for DNA extractions in order to identify the blood source.

\section{Identification of meal sources in blood-fed mosquitoes}

Mosquitoes collected in the field were individually placed in $1.5 \mathrm{ml}$ plastic tubes containing silica gel desiccant and stored at $-10^{\circ} \mathrm{C}$ until processed. Engorged abdomens were separated from the rest of the body for blood source identification.

DNA was extracted from the blood in each abdomen using the REDExtract-N-Amp ${ }^{\text {TM }}$ Tissue PCR Kit (SIGMA, St. Louis, MO, USA) per the manufacturer's instructions. Species identification of the host blood source was performed by 2 different methods; multiplex PCR as described by Kent and Norris [21], or direct sequencing as described by Sawabe et al. [22].

Multiplex PCR was carried out using published cytochrome-B primers for human (Human741F, ggcttacttctctt cattctctcct) and cow (Cow121F, catcggcacaaatttagtcg) and a universal reverse primer (UNREV1025, ggttgtcctccaatt catgtta) [21]. A $20 \mu \mathrm{l}$ cocktail consisting of $0.5 \mu \mathrm{M}$ of each primer and previously diluted (300 times) $1 \mu \mathrm{l}$ of the DNA template was placed in a $0.2 \mathrm{~mL}$ cell containing lyophilized AccuPower ${ }^{\mathrm{TM}}$ PCR Premix (BIONEER, Daejeon, Korea). The PCR was performed under the following conditions: a hot start at $95^{\circ} \mathrm{C}$ for $5 \mathrm{~min} ; 35$ cycles of template denaturing at $95^{\circ} \mathrm{C}$ for $1 \mathrm{~min}$, primer annealing at $54^{\circ} \mathrm{C}$ for $1 \mathrm{~min}$, and amplicon extension at $72^{\circ} \mathrm{C}$ for $1 \mathrm{~min}$; and a final extension at $72^{\circ} \mathrm{C}$ for 7 min. Human and cow blood was detected by agarose gel electrophoresis (2\% TAE) as 334 bp and 561 bp bands, respectively [21].

PCR amplification to generate amplicons for sequencing was done using published primers VerU-1 (aagacga gaagacccyatgga) and VerU-2 (cctgatccaacatmgaggtcgta) designed to detect the cytochrome- $\mathrm{B}$ gene of vertebrates; and Mammalian-1 (tgayatgaaaaaycatcg) and Mammalian2 (tgtagttrtcwgggtckccta) cytochrome-B designed to detect the cytochrome-B gene of mammals [22]. The PCR mixture contained $4 \mu$ l of REDExtract-N-Amp ${ }^{\mathrm{TM}}$ ReadyMix cytochrome-B (SIGMA, St. Louis, MO, USA), $0.5 \mu \mathrm{M}$ of each primer, and $1 \mu \mathrm{l}$ of the DNA template in a total volume of $10 \mu \mathrm{l}$. PCR was conducted under the following conditions: a hot start of $94^{\circ} \mathrm{C}$ for $2 \mathrm{~min}$; 35 cycles of template denaturing at $94^{\circ} \mathrm{C}$ for $30 \mathrm{sec}$, primer annealing at $55^{\circ} \mathrm{C}$ for $30 \mathrm{sec}$, and amplicon extension at $72^{\circ} \mathrm{C}$ for $1 \mathrm{~min}$; and a final extension at $72^{\circ} \mathrm{C}$ for $4 \mathrm{~min}$. Direct sequencing was performed with a 3730 DNA Analyzer (Applied Biosystems, Carlsbad, CA, USA). The results were analyzed by MEGA 4.0 public domain software (http://www.megasoftware.net/). Sequences were used to perform basic local alignment searches against Genbank (National Center for Biotechnology Information website http://ww.ncbi.nlm.nih.gov/BLAST/) to determine the identities of the host species [22].

\section{Detection of $P$. falciparum in mosquitoes}

Evidence of the presence of $P$. falciparum was first determined by enzyme-linked immunosorbent assay (ELISA). The head and thorax of each mosquito was homogenized in phosphate buffered saline ( $\mathrm{pH}$ 7.4) and tested for the circumsporozoite antigen using a monoclonal antibody ELISA [23]. ELISA positive samples were confirmed by a Plasmodium specific PCR. DNA extraction was performed on the QIAcube (kit AIAamp DNA Micro Kit 56304, Qiagen, Tkyo, Japan) following the manufacturer's instructions and the methods by Durnez et al. [24]. A $20 \mu \mathrm{l}$ aliquot of the ELISA-lysate was added to $80 \mu \mathrm{l}$ of ATL-buffer and extracted in the QIAcube machine, which eluted the DNA in $50 \mu \mathrm{l}$ AE-buffer. The pestles used in the extraction had been sterilized in $\mathrm{HCl}$ solution to prevent contamination. The nested PCR was carried out according to the methods by Snounou et al. [25]. The first amplification was done using published primers rPLU-5 (cctgttgttgccttaaacttc) and rPLU-6 (ttaaaattgttgcagttaaaacg). The PCR mixture contained $0.4 \mu \mathrm{l}$ of Mighty Amp DNA Polymerase (Takara Bio, Inc., Tokyo, Japan), $0.6 \mu \mathrm{M}$ of each primer, and $1 \mu \mathrm{l}$ of the DNA template in a total volume of $20 \mu \mathrm{l}$. PCR was conducted under the following conditions: a hot start of $98^{\circ} \mathrm{C}$ for $2 \mathrm{~min}$; 35 cycles of template denaturing at $98^{\circ} \mathrm{C}$ for $10 \mathrm{sec}$, primer annealing at $58^{\circ} \mathrm{C}$ for $15 \mathrm{sec}$, and amplicon extension at $68^{\circ} \mathrm{C}$ for $1 \mathrm{~min}$; and a final annealing at $57^{\circ} \mathrm{C}$ for $2 \mathrm{~min}$ and extension at $72^{\circ} \mathrm{C}$ for $4 \mathrm{~min}$. The 2nd amplification was done using Plasmodium falciparum specific primers rVIV1 (cgct tctagcttaatccacataactgatac) and rVIV2 (acttccaagccgaag caaagaaagtcctta). The PCR mixture contained $0.2 \mu \mathrm{l}$ of Mighty Amp DNA Polymerase (Takara Bio, Inc., Tokyo, Japan), $0.3 \mu \mathrm{M}$ of each primer, and $1 \mu \mathrm{l}$ of the DNA template in a total volume of $10 \mu \mathrm{l}$. PCR was conducted under the following conditions: a hot start of $98^{\circ} \mathrm{C}$ for $2 \mathrm{~min}$; 35 cycles of template denaturing at $98^{\circ} \mathrm{C}$ for $10 \mathrm{sec}$, primer annealing at $58^{\circ} \mathrm{C}$ for $15 \mathrm{sec}$, and amplicon extension at $68^{\circ} \mathrm{C}$ for $30 \mathrm{sec}$; and a final annealing at $57^{\circ} \mathrm{C}$ for $2 \mathrm{~min}$ and extension at $72^{\circ} \mathrm{C}$ for 4 $\min$.

\section{Insecticide susceptibility tests using World Health Organization test tubes for F1 progenies}

Adult susceptibility tests to insecticides was done using World Health Organization (WHO) test tube kits for F1 progenies and performed according to WHO instructions (WHO/CDS/CPC/MAL/98.12). Papers impregnated with either $0.75 \%$ permethrin, $0.05 \%$ deltamethrin, $4 \%$ DDT, $1 \%$ fenitrothion, or $0.1 \%$ propoxur were used for the tests. F1 larvae from the separate egg batches oviposited by field collected females were pooled in one batch to get adult females. Ten F1 1-3-day-old female mosquitoes were released into WHO test tubes for 
exposure to insecticide-impregnated paper for one hour, and the time to knockdown was recorded. One hr exposure to fenitrothion was performed in our bioassay, although $2 \mathrm{hr}$ is stipulated in WHO instructions. Insects were then transferred to a clean tube, fed via cotton soaked with a $5 \%$ glucose solution, and mortality was recorded after one day. $\mathrm{KT}_{50}$ (time required for $50 \%$ knockdown) was obtained and average mortality was calculated. Two to 4 replications were performed for each insecticide. Control test was performed in each replication.

\section{Species identification}

Mosquito adults were examined microscopically to distinguish $A n$. funestus s.l. from other anophelines based on identification keys developed by Gillies and Coetzee [26]. Individual species within An. funestus s.l. were identified using the multiplex polymerase chain reaction (PCR) method described by Koekemoer et al. [27].

\section{Data analysis}

$\mathrm{KT}_{50}$ was calculated by Bliss' probit method [28]. Mosquito densities were calculated as the mean number of female mosquitoes collected per collection time (2 hours) per house. The data for each replication were excluded from analysis when the total number of mosquitoes collected during a night was less than 5 .

\section{Results}

Species abundance, $P$. falciparum sporozoite rate and blood meal composition

The total number of $A n$. funestus s.l. female mosquitoes collected in the Gembe East area is shown in Table 1. The number of $A n$. funestus s.s. was higher than $A n$. rivulorum throughout the year in 2010. In contrast, the species composition was reversed in 2012.

Of the 250 An. funestus s.s. and 284 An. rivulorum female mosquitoes used, $5(2.0 \%)$ and 5 (1.76\%) females were found to be $P$. falciparum positive by CSP-ELISA and $2(0.80 \%)$ and $2(0.70 \%)$ females were $P$. falciparum positive by PCR detection, respectively (Table 2 ).

Table 1 Species composition of An. funestus s.l. collected in the Gembe East area in western Kenya

\begin{tabular}{|c|c|c|c|c|c|}
\hline \multirow[t]{3}{*}{ Species } & \multicolumn{5}{|c|}{ Collection date - No. of females collected } \\
\hline & \multicolumn{3}{|c|}{2010} & \multicolumn{2}{|c|}{2012} \\
\hline & Feb-Mar & Apr-Jul & Sept-Nov & Jan-Mar & Jul \\
\hline An. funestus s.s. & 74 & 686 & 732 & 21 & 56 \\
\hline An. rivulorum & 0 & 58 & 373 & 235 & 107 \\
\hline (An. rivulorum \%) & $(0.0)$ & $(7.8)$ & $(33.8)$ & $(91.8)$ & $(65.6)$ \\
\hline An. gambiae s.s. & 1 & 8 & 1 & $N A^{1)}$ & NA \\
\hline An. arabiensis & 31 & 67 & 33 & NA & NA \\
\hline
\end{tabular}

1) NA: Collection of An. gambiae group was not done.
Blood meal compositions for the 2 species are shown in Table 3. Proportion of human blood was higher in An. funestus s.s. $(48.0 \%-50.7 \%)$ as compared to that in An. rivulorum (6.7\%-16.0\%). An. rivulorum was found to feed on various animals such as cows, bats, birds, apes, mice, bushbuck, and hippopotami; in comparison, An. funestus s.s. fed on cows, bats, and dogs.

\section{Indoor flight activity pattern of An. rivulorum females trapped by CDC miniature traps equipped with a collection bottle rotator}

The houses used for indoor mosquito collections were of standard construction for the area, with mud walls and eaves, traditional opening structures between the roof and the walls, and divided into 1-2 bedrooms and 1 living room. The number of ITNs used in each household ranged from $0-2$ (average 0.8 net/house), with $0-3$ people sleeping in each bedroom (average 2.0 persons/ bed room), and $0-4$ people (mainly children $>5$ years old) sleeping in each living room without ITNs (average 1.8 persons/living room). The number of cows, sheep, and goats reared around each house ranged from 0-17 (average 12.2), 0-8 (average 4.4), and 0-9 (average 6.0), respectively.

Among the 31 collections conducted, 13 were not used due to $<5$ mosquitoes collected on that night, and 4 collections had to be discarded due to equipment malfunction. The remaining 14 collections were used for analysis.

The number of trapped $A n$. rivulorum females rose sharply during early evening (18:00-20:00), falling drastically after this period (Figure 1). The number of bloodfed females also peaked in this period. Among the 249 females collected, 104 were unfed (41.8\%), 20 contained blood from a human source (8.1\%), and 125 had fed from an animal source (50.2\%). Among the 20 females engorged with human blood, 13 (65\%) were trapped in the 18:00-20:00 period.

Insecticidal susceptibility of An. funestus s.l. female adults Insecticide susceptibility of adult F1 An. funestus s.l. female mosquitoes is shown in Figure 2.

An. funestus s.s. showed high resistance to both permethrin and deltamethrin (36.8\% and $36.4 \%$ mortality, both $>60$ min $\mathrm{KT}_{50}$, respectively), while the resistance against DDT was lower (70.0\% mortality and $29 \mathrm{~min}$ $\left.\mathrm{KT}_{50}\right) . \mathrm{KT}_{50}$ and mortality for propoxur and fenitrothion were $23.2 \mathrm{~min}-100 \%$, and $>60 \mathrm{~min}-100 \%$, indicating that $A n$. funestus s.s. is susceptible to these insecticides. Susceptibility of An. rivulorum to pyrethroids was higher compared to $A n$. funestus s.s. but resistance was suspected in this species according to WHO criteria, since mortalities to permethrin and deltamethrin were less than $100 \%$ (84.8\% and $91.4 \%$, respectively), while $\mathrm{KT}_{50} \mathrm{~S}$ 
Table 2 Plasmodium falciparum sporozoite rate in An. funestus s.l. collected in the Gembe East area in western Kenya, Sept-Oct 2010

\begin{tabular}{lllll}
\hline \multicolumn{1}{c}{ Species } & No. of females used & No. of $\boldsymbol{P}$. falciparum positive (ELISA) & No. of $\boldsymbol{P}$. falciparum positive (PCR) & \% positive \\
\hline An. funestus S.S. & 250 & 5 & 2 & 0.80 \\
An. rivulorum & 284 & 5 & 2 & 0.70 \\
\hline
\end{tabular}

were smaller than those in An. funestus s.s. (30.5 min and $25.5 \mathrm{~min}$, respectively). Susceptibility of $A n$. rivulorum against DDT, propoxur, and fenitrothion was high (25 min $\mathrm{KT}_{50}-100 \%$ mortality, 17 min $\mathrm{KT}_{50}-100 \%$ mortality, and $>60$ min $\mathrm{KT}_{50}-100 \%$ mortality, respectively).

\section{Discussion}

The importance of $A n$. rivulorum as a vector of human malaria in Africa was first advocated by Wilkes et al. in 1996 [29]. Most of the mosquito sampling in that study was done at resting sites close to cattle corrals and pit shelters. All-night landing catches on human bait were done outdoors, since this species was considered to be exophilic and zoophilic [4]. Some reports, however, presented evidence that this species was neither completely exophilic nor zoophilic. Oyewole and Awolola reported that $42 \%$ of $A n$. rivulorum in Lagos, Nigeria was collected indoors [8]. All mosquito collections were performed indoors in the current study. The increase in the proportion of $A n$. rivulorum from 2010 to 2012 possibly seemed to be due to a rise in the availability of larval habitats. Larvae of $A n$. rivulorum are closely associated with aquatic vegetation, such as the water hyacinths in Lake Victoria, and the fluctuation of the lake water levels may have affected habitat availability [30].

Plasmodium falciparum in An. rivulorum was absent or low in previous reports: $0 \%(0 / 80)$ [7], $0 \%(0 / 90)$ [8], $0 \%(0 / 264)$ [10], and $0.5 \%(1 / 203)$ [29]. Wilkes et al. reported that $0.5 \%$ of $A n$. rivulorum (5/1022) was positive via observation of sporozoites using a compound microscope, and that 1 of the 2 samples examined by ELISA was $P$. falciparum positive [29]. Temu et al. detected 2 Pf positive individuals in $10 \mathrm{An}$. rivulorum when examined by nested polymerase chain reaction
(PCR), although the number of samples was not enough to be statistically evaluated [6]. The $P$. falciparum positive rate for $A n$. rivulorum in the present study (0.70\%) seemed to be relatively high compared to previous reports.

Anopheles rivulorum is more zoophilic than An. funestus s.s. and a broad range of animals were found to be serving as hosts. Host preference, however, appears to be affected by the human/animal ratio, as mosquitoes are more zoophilic in an area where animals are more abundant than humans [31]. A high level of anthropophily in An. rivulorum was reported by Kweka et al. [7], indicating that $64.5 \%$ of $A n$. rivulorum sampled in northeastern Tanzania had taken a blood meal from a human host. Awolola et al. reported that $39.6 \%$ of An. rivulorum were found to have ingested human blood in a forest area of southern Nigeria [10]. Likewise, Wilkes et al. collected a number of $A n$. rivulorum using human bait ( $>14$ females/h) [29]. The evidence above indicates that this species has the potential to be a transmitter of human malaria. In our study, a remarkable flight activity peak of $A n$. rivulorum was observed in the early evening (18:00-20:00), indicating that this species prefers to feed during a period before humans are likely to be in bed and under an ITN. These data correlate with the results shown by Wilkes et al. using human bait [29].

The difference in pyrethroid susceptibilities between An. funestus s.s. and An. rivulorum may be explained by the different probabilities of each species coming into contact with the pyrethroids thought to be used exclusively in ITNs. An. funestus s.s. and 2 other major vectors in the study area, $A n$. gambiae s.s. and $A n$. arabiensis, have developed high pyrethroid resistance via unique mechanisms [14,15]. Pyrethroid resistance in $A n$. gambiae s.s. has developed by the dramatic increase of

Table 3 Blood meal composition in female An. funestus s.l. collected in the Gembe East area in western Kenya

\begin{tabular}{|c|c|c|c|c|c|c|}
\hline & \multirow{2}{*}{$\begin{array}{l}\text { Detection } \\
\text { method }\end{array}$} & \multirow{2}{*}{$\begin{array}{c}\text { No. } \\
\text { examined }\end{array}$} & \multirow{2}{*}{$\begin{array}{c}\text { Human } \\
\text { blood } \\
(\%)\end{array}$} & \multirow{2}{*}{$\begin{array}{c}\text { Cow } \\
\text { blood } \\
(\%)\end{array}$} & \multicolumn{2}{|r|}{ Others } \\
\hline & & & & & No. (\%) & Species \\
\hline \multirow[t]{2}{*}{ An. funestus s.s. } & Direct sequencing & $25^{a}$ & $12(48.0)$ & $16(64.0)$ & $5(20.0)$ & bats, dogs \\
\hline & PCR & $69^{b}$ & $35(50.7)$ & $4(5.8)$ & $32(46.4)$ & - \\
\hline \multirow[t]{2}{*}{ An. rivulorum } & Direct sequencing & $148^{\mathrm{a}}$ & $24(16.0)$ & $145(98.0)$ & $24(16.0)$ & bats, birds, apes, mice, bushbuck, hippopotami \\
\hline & PCR & $89^{c}$ & $6(6.7)$ & $33(37.1)$ & $53(59.6)$ & - \\
\hline
\end{tabular}

\footnotetext{
a) collected in Oct 2011.

b) collected in Feb 2011 and Feb 2012

c) collected in Jan 2012.
} 


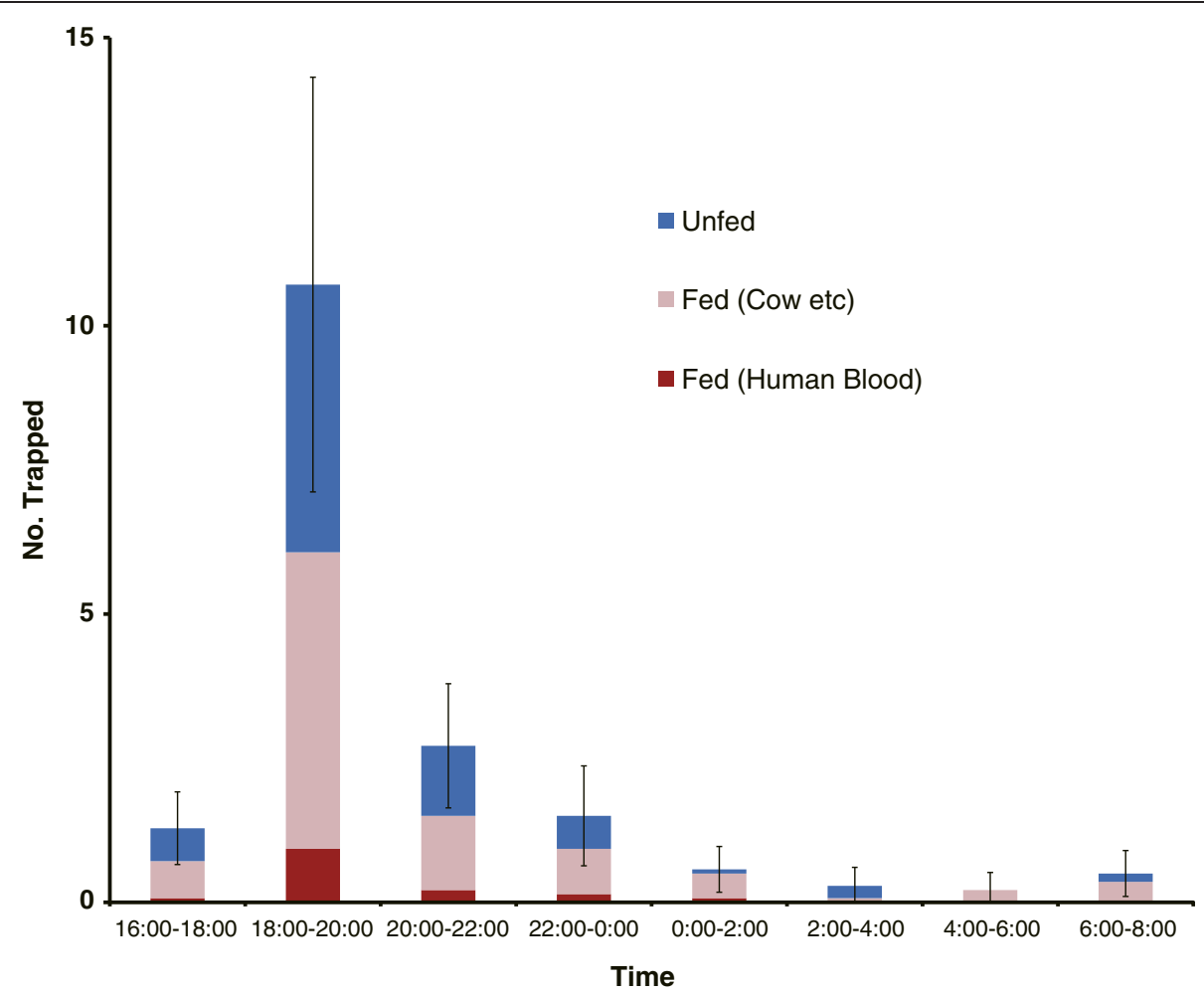

Figure 1 Indoor activity pattern of An. rivulorum females. Indoor activity pattern of An. rivulorum females trapped by Center for Disease Control miniature traps equipped with a collection bottle rotator. Bars indicate $95 \%$ confidential limits in total number of mosquitoes collected in each collection times.

the L1014S mutation in the voltage gated sodium channel $(k d r)$, and mixed function oxydase-related metabolic resistance has developed in both An. arabiensis and $A n$. funestus s.s. [14]. These resistances were thought to be caused solely by wide-spread distribution of ITNs containing pyrethroids in the study area during the past decade. Indoor spraying with residual insecticides has not been done in the study area [14]; therefore, neither carbamates nor organophosphates are supposed to have been used to control malaria vectors. However, the

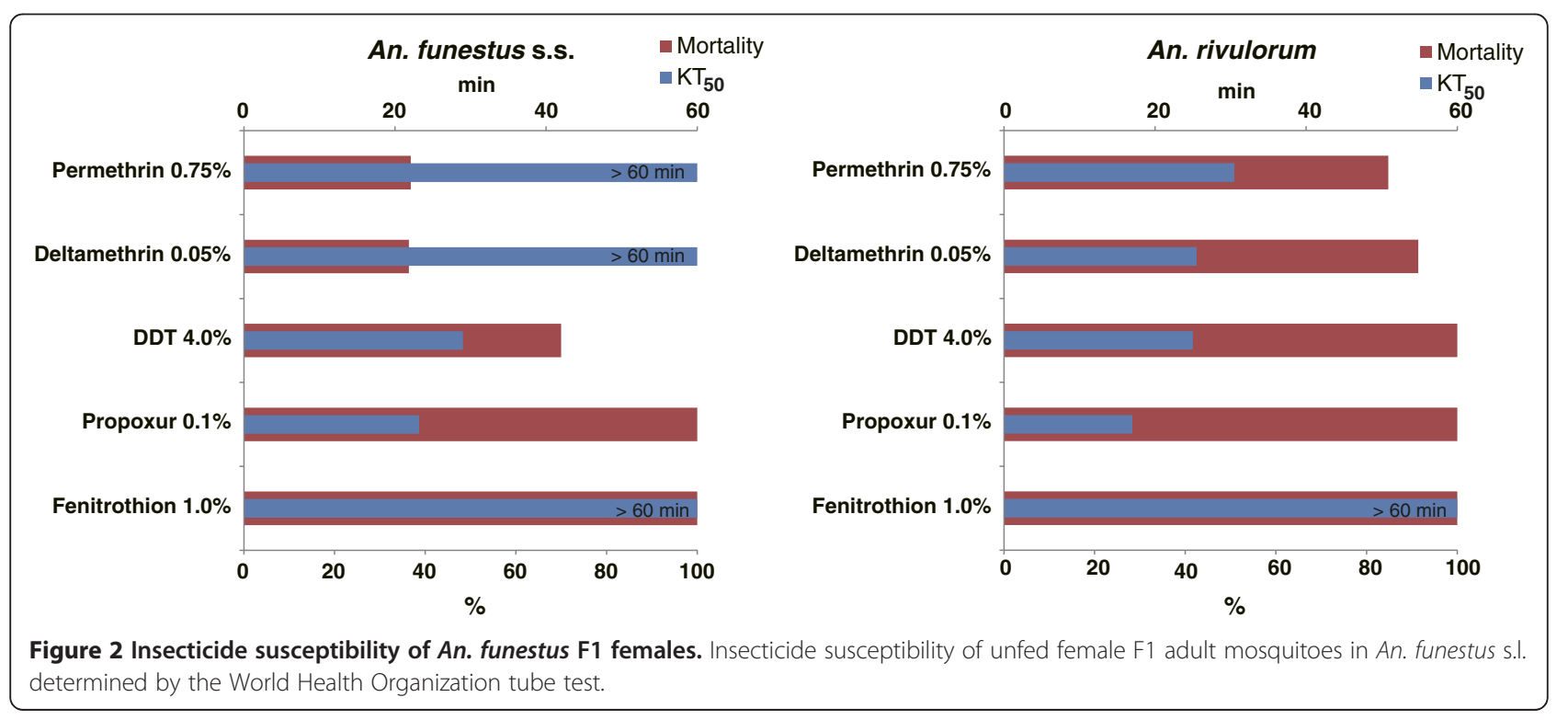


chance of $A n$. rivulorum being exposed to the pyrethroids impregnated in most of the ITNs seems to be low compared to other vector species, as most of the feeding in this species takes place in early evening. Although most people may not be under the ITNs early in evening, the nets are still in houses hung or folded, making a chance of exposure for mosquitoes. The mortalities on permethrin and deltamethrin $(<100 \%)$ indicate that the selection pressure of pyrethroids on this species is not negligible. The monitoring of pyrethroid resistance is therefore necessary in $A n$. rivulorum as in the other vector species.

\section{Conclusion}

In conclusion, the present report clarifies that $A n$. rivulorum feeds on human blood, especially in early evening when ITNs are not in use. Plasmodium falciparum sporozoites were detected in $0.70 \%$ of mosquitoes tested, and presents data indicating a possibility that this species has developed pyrethroid resistance according to the latest WHO criteria (Global Plan for Insecticide Resistance Management in Malaria Vectors; http://www.who.int/malaria/vector_control/ivm/gpirm/en/index.html). Therefore, we strongly recommend that the latent ability of this species as a minor vector should be reconsidered and that the urgent need for implementation of a resistance management strategy for such species. The development of new technologies to control such malaria vectors will also be essential [32].

\section{Competing interests}

The authors declare that they have no competing interests.

\section{Authors' contributions}

HK designed the study, carried out the experiments, and drafted the manuscript. GOD and GS arranged the fields and informed consents of the participants for the study and organized the staffs for the experiments. SMN, CM, and NM critically revised the protocol for the study. All authors read and approved the final version of the manuscript.

\section{Acknowledgements \\ This study was funded by a joint research effort between Nagasaki University and Sumitomo Chemical Co. Ltd to create field and semi-field bioassay systems for delivering new insecticide technology. The protocol for the study (case No. 1775) was reviewed and approved by the Scientific Steering Committee (SSC) and the National Ethics Review Committee (ERC) of the Kenya Medical Research Institute (KEMRI). We are grateful to the staff at the Thomas Odhiambo campus of the International Center of Insect Physiology and Ecology (ICIPE) for providing facilities and experimental insects. We also thank P. Lutiali, M. Syombua, J. Kongere, S. Wagalla, J. Lumumba, NUITM- KEMRI Project, Kenya Research Station, Nairobi, Kenya, F. Sonye, A. Oreng' Obielo, G. Juma, G. Opiyo, Springs of Hope, Mbita, Kenya, and E. Kawashima, H. Iwashita, K. Minagawa, C. Kimura, Institute of Tropical Medicine, Nagasaki University, Nagasaki, Japan, for providing technical support and assisting with this study.}

\section{Author details}

${ }^{1}$ Department of Vector Ecology \& Environment, Institute of Tropical Medicine, Nagasaki University, Nagasaki, Japan. ${ }^{2}$ School of Public Health, Maseno University, Kisumu, Kenya. ${ }^{3}$ Springs of Hope, Mbita, Kenya. ${ }^{4}$ Eastern and Southern Africa Centre of International Parasite Control, Nairobi, Kenya.
${ }^{5}$ Kenya Medical Research Institute, Nairobi, Kenya. ${ }^{6}$ The Global Center of Excellence Program, Nagasaki University, Nagasaki, Japan.

Received: 30 August 2012 Accepted: 5 October 2012

Published: 10 October 2012

\section{References}

1. Mbogo CN, Kabiru EW, Muiruri SK, Nzovu JM, Ouma JH, Githure Jl, Beier JC: Bloodfeeding behavior of Anopheles gambiae s.l. and Anopheles funestus in Kilifi District, Kenya. J Am Mosa Control Assoc 1993, 9:225-227.

2. Githeko AK, Service MW, Mbogo CM, Atieli FK, Juma FO: Origin of blood meals in indoor and outdoor resting malaria vectors in western Kenya. Acta Trop 1994, 58:307-316.

3. Muriu SM, Muturi EJ, Shililu JI, Mbogo CM, Mwangangi JM, Jacob BG, Irungu LW, Mukabana RW, Githure Jl, Novak RJ: Host choice and multiple blood feeding behaviour of malaria vectors and other anophelines in Mwea rice scheme. Kenya. Malaria J 2008, 7:43.

4. Gillies MT, De Meillon B, Gillies MT, De Meillon B: The Anophelinae of Africa South of the Sahara. In Publications of the South African Institute for Medical Research, Volume 54. Johannesburg: 1968.

5. Hargreaves K, Koekemoer LL, Brooke BD, Hunt RH, Mthembu J, Coetzee M: Anopheles funestus resistant to pyrethroid insecticides in South Africa. Med Vet Entomol 2000, 14:181-189.

6. Temu EA, Minjas JN, Tuno N, Kawada H, Takagi M: Identification of four members of the Anopheles funestus (Diptera: Culicidae) group and their role in Plasmodium falciparum transmission in Bagamoyo coastal Tanzania. Acta Trop 2007, 102:119-125.

7. Kweka EJ, Mahande AM, Nkya WM, Assenga C, Lyatuu EE, Nyale E, Mosha FW, Mwakalinga SB, Temu EA: Vector species composition and malaria infectivity rates in Mkuzi, Muheza District, north-eastern Tanzania. Tanzan J Health Res 2008, 10:46-49.

8. Oyewole 10, Awolola TS: Impact of urbanization on bionomics and distribution of malaria vectors in Lagos, southern Nigeria. J Vect Borne Dis 2006, 43:173-178.

9. Awolola TS, Ibrahim K, Okorie T, Koekemoer LL, Hunt RH, Coetzee M: Species composition and biting activities of anthropophilic Anopheles mosquitoes and their role in malaria transmission in a holoendemic area of southern Nigeria. African Entomol 2003, 11:227-232.

10. Awolola TS, Oyewole IO, Koekemoer LL, Coetzee M: Identification of three members of the Anopheles funestus (Diptera: Culicidae) group and their role in malaria transmission in two ecological zones in Nigeria. Trans $R$ Soc Trop Med Hyg 2005, 99:525-531.

11. Gillies MT, Smith A: The effect of a residual house spraying campaign in East Africa on species balance in the Anopheles funestus group: the replacement of Anopheles funestus Giles by Anopheles rivulorum Leeson. Bull Entomol Res 1960, 51:243-252.

12. Binka FN, Kubaje A, Adjuik M, Williams LA, Lengeler C, Maude GH, Armah GE, Kajihara B, Adiamah JH, Smith PG: Impact of permethrin treated bednets in child mortality in Kassena-Nankana district, Ghana: a randomized controlled trial. Trop Med Int Health 1996, 1:147-154.

13. Nevill CG, Some ES, Mung'ala VO, Mutemi W, New L, Marsh K, Lengeler C, Snow RW: Insecticide-treated bed nets reduce mortality and severe morbidity from among children on the Kenyan Coast. Trop Med Int Health 1996, 1:139-146.

14. Kawada H, Dida GO, Ohashi K, Komagata O, Kasai S, Tomita T, Sonye G, Maekawa Y, Mwatele C, Njenga SM, Mwandawiro C, Takagi M: Multimodal pyrethroid resistance in malaria vectors, Anopheles gambiae s.s., Anopheles arabiensis, and Anopheles funestus s.s. in western Kenya. PLoS One 2011, 6:e22574.

15. Kawada H, Futami K, Komagata O, Kasai S, Tomita T, Sonye G, Mwatele C, Njenga SM, Mwandawiro C, Minakawa N, Takagi M: Distribution of a knockdown resistance mutation (L1014S) in Anopheles gambiae s.s. and Anopheles arabiensis in Western and Southern Kenya. PLoS One 2011, 6:e24323.

16. Mathias D, Ochomo EO, Atieli F, Ombok M, Bayoh MN, Olang G, Muhia D, Kamau L, Vulule JM, Hamel MJ, Hawley WA, Gimnig JE: Spatial and temporal variation in the kdr allele L1014S in Anopheles gambiae s.s. and phenotypic variability in susceptibility to insecticides in Western Kenya. Malaria J 2011, 10:10.

17. Bayoh MN, Mathias DK, Odiere MR, Mutuku FM, Kamau L, Gimnig JE, Vulule JM, Hawley WA, Hamel MJ, Walker ED: Anopheles gambiae: historical 
population decline associated with regional distribution of insecticidetreated bed nets in western Nyanza Province Kenya. Malaria J 2010, 9:62.

18. Gouagna LC, Okech BA, Kabiru EW, Killeen GF, Obare P, Ombonya S, Bier JC, Knols BG, Githure JI, Yan G: Infectivity of Plasmodium falciparum gametocytes in patients attending rural health centers in western Kenya. East Afr Med J 2003, 80:627-634.

19. Noor AM, Patil AP, Hay SI, Muchiri E, Patil AP, Hay SI, Muchiri E, Muchiri E, Muchiri E, Alegana1 VA: The risks of malaria infection in Kenya in 2009. BMC Infect Dis 2009, 9:180,

20. Tuno N, Githeko AK, Nakayama T, Minakawa N, Takagi M, Yan G: The association between the phytoplankton, Rhopalosolen species (Chlorophyta; Chlorophyceae), and Anopheles gambiae sensu lato (Diptera: Culicidae) larval abundance in western Kenya. Ecol Res 2006, 21:476-482

21. Kent BJ, Norris DE: Identification of mammalian blood meals in mosquitoes by a multiplexed polymerase chain reaction targeting cytochrome B. Am J Trop Med Hyg 2005, 73:336-342.

22. Sawabe K, Isawa H, Hoshino K, Sasaki T, Roychoudhury S, Higa Y, Kasai S, Tsuda Y, Nishiumi I, Hisai N, Hamao S, Kobayashi M: Host-feeding habits of Culex pipiens and Aedes albopictus (Diptera: Culicidae) collected at the urban and suburban residential areas of Japan. J Med Entomol 2010, 47:442-450.

23. Wirtz RA, Zavala F, Charoenvit Y, Campbell GH, Burkot TR, Schneider I, Esser KM, Beaudoin RL, Andre RG: Comparative testing of monoclonal antibodies against Plasmodium falciparum sporozoites for ELISA development. Bull WHO 1987, 65:39-45.

24. Durnez L, Van Bortel W, Denis L, Roelants P, Veracx A, Trung HD, Sochantha T, Coosemans M: False positive circumsporozoite protein ELISA: a challenge for the estimation of the entomological inoculation rate of malaria and for vector incrimination. Malaria J 2011, 10:195.

25. Snounou G, Viriyakosol S, Zhu XP, Jarra W, Pinheiro L, Do Rosario VE, Thaithong S, Brown KN: High sensitivity of detection of human malaria parasites by the use of nested polymerase chain reaction. Mol Biochem Parasitol 1993, 61:315-320.

26. Gillies MT, Coetzee M: A supplement to the Anophelinae of Africa south of the Sahara (Afrotropical region). In South African Institute for Medical Research, Volume 55; 1987.

27. Koekemoer LL, Kamau L, Hunt RH, Coetzee M: A cocktail polymerase chain reaction (PCR) assay to identify members of the Anopheles funestus (Diptera: Culicidae) group. Am J Trop Med Hyg 2002, 66:804-811.

28. Bliss Cl: The method of probits - A correction. Science 1934, 79:409-410.

29. Wilkes TJ, Matola YG, Charlwood JD: Anopheles rivulorum, a vector of human malaria in Africa. Med Vet Entomol 1996, 10:108-110.

30. Minakawa N, Dida GO, Sonye GO, Futami K, Njenga SM: Malaria vectors in Lake Victoria and adjacent habitats in western Kenya. PLoS One 2012, 7:e32725.

31. Tirados I, Costantini C, Gibson G, Torr SJ: Blood-feeding behaviour of the malarial mosquito Anopheles arabiensis: implications for vector control. Med Vet Entomol 2006, 20:425-437.

32. Kawada H, Dida GO, Ohashi K, Sonye G, Njenga SM, Mwandawiro C, Minakawa N, Takagi M: Preliminary evaluation of the insecticideimpregnated ceiling nets with coarse mesh size as a barrier against the invasion of malaria vectors. Jpn J Infect Dis 2012, 65:243-246.

\section{doi:10.1186/1756-3305-5-230}

Cite this article as: Kawada et al.: Reconsideration of Anopheles rivulorum as a vector of Plasmodium falciparum in Western Kenya: some evidence from biting time, blood preference, sporozoite positive rate, and pyrethroid resistance. Parasites \& Vectors 2012 5:230. 